$<13$ yoa tended to use the Playroom. Most of the adolescents and their parents felt that their recreational needs were not met. Parents generally advocated for the presence of a 'Teen Den' as opposed to Playroom. All adolescents either preferred the idea of a Teen Den or were indifferent towards it. Some parents of children $<13$ yoa were 'bothered' that adolescents could have use of the same Playroom as their children.

Conclusion The establishment of an adolescent-specific recreational area for adolescents admitted to the Paediatric Ward in Sligo University Hospital should be established to cater for their recreational needs and well-being. Adolescents on the Paediatric Ward should have different accommodation to younger children.

\section{GP101 THE IMPACT OF AN INFORMATION LEAFLET ON PARENTAL KNOWLEDGE, ANXIETY AND SATISAFACTION IN AN IRISH PAEDIATRIC COMPUTED TOMORGAPPHY DEPARTMENT}

Niabh Kirk*, Colm Saidlear. Children's Health Ireland, Dublin, Ireland

\subsection{6/archdischild-2019-epa.166}

Background There is little research into the impact of information in the radiology setting.

In the surgical setting written information has demonstrated many strengths in educating parents, improving outcomes and reducing parental and patient anxiety.

Aims and objectives The aim of this work was to evaluate the impact of an information leaflet on parental knowledge, anxiety and satisfaction in a paediatric CT Department.

It also aimed to identify parental information seeking behaviours.

Methods/Intervention A prospective, mixed-methods study was performed. Routine verbal information was provided to a Control group while a Study group received an information leaflet. Both groups completed two questionnaires. One employed multi-choice questions to evaluate parental knowledge, information seeking behaviours and causes of anxiety. The second assessed anxiety and satisfaction using visual analogue scales.

Results/Findings For parental knowledge of CT, the Study group demonstrated higher results

$($ mean $=5.71$, median $=6)$ compared with the Control group $($ mean $=4.67$; median $=4)$ for correct answers. They also scored marginally lower for the number of incorrect responses.

The mean rank for anxiety in the Study group (9.93) was much lower in comparison with the Control group (19.73) while satisfaction amongst the

Study group was higher (18.68 vs. 11.57). These differences were statistically significant $(\mathrm{p}=0.002 ; \mathrm{p}=0.023$; $\mathrm{p}<0.05)$.

More of the Study group (36\% vs. 7\%) sought further information prior to attending for the appointment suggesting that the leaflet encouraged parents to ask more questions. Furthermore, when participants were asked if they would've preferred further information before the appointment, more from the Control group (40\% vs. 14\%) answered positively.
Conclusions This study has demonstrated that the information leaflet did have a positive impact on parental anxiety and satisfaction but not parental knowledge.

(An electronic poster on this project will be presented at the European Congress of Radiology March 2019).

\section{GP102 PAEDIATRIC ABDOMINAL X-RAYS: APPROPRIATE OR UNNECESSARY REQUESTS?}

${ }^{1}$ Ciara Ryan*, ${ }^{2}$ Peter Tormey, ${ }^{1,2}$ Edina Moylett. 'Academic Department of Paediatrics, National University of Ireland, Galway, Galway, Ireland; '2Department of Paediatrics, University Hospital Galway, Galway, Ireland

\subsection{6/archdischild-2019-epa.167}

Introduction Paediatricians play a significant role in preventive healthcare ${ }^{1}$. There is a strong link between radiation exposure and the development of cancer ${ }^{2}$. The typical dose of radiation required for an abdominal $\mathrm{x}$-ray (AXR) is $0.46 \mathrm{mSv}$, which is the equivalent approximate dose to 35 chest $\mathrm{x}$-rays ${ }^{3}$. AXRs are frequently ordered for children in our hospital by staff in paediatric, surgical and Emergency Departments (ED) who may be unaware of the guidelines surrounding clinical indications for AXRs.

Aims To review the indications for paediatric AXRs requested in our hospital and compare them to the Royal Children's Hospital, Melbourne (RCHM) Guidelines ${ }^{4}$, which are considered the gold standard.

Methods AXRs performed in University Hospital Galway from 1st June - 30th November 2018, on children $\leq 14$ years old, were identified. Those ordered from the Neonatal Intensive Care Unit and those ordered directly by the patient's General Practitioner were excluded. Details including patient age, clinical indication, requesting specialty, existing diagnoses and previous presentations with the same complaint were collected from the online radiology system.

Results A total of 132 AXRs were identified, 83 of which were included in the analysis. In accordance with RCHM guidance, $49.4 \% \quad(n=41)$ of requests were appropriate. Bowel obstruction and foreign body ingestion were the commonest indications for appropriate requests; constipation and non-specific abdominal pain were the commonest inappropriate requests. The paediatric department requested 55 AXRs, 49\% $(n=27)$ considered appropriate; the surgical department requested 9, zero considered appropriate. The ED requested 17 AXRs, $70.5 \% \quad(n=12) \quad$ considered appropriate.

Conclusion During the 6-month period, over half of the AXR requests were deemed inappropriate and may have been avoided. Further education concerning AXR indications should be directed at paediatric and surgical teams primarily to minimise unnecessary investigations and limit radiation exposure.

\section{REFERENCES}

1. Chang VY, Davidson TB (2015). Childhood Exposures and Risk of Malignancy in Adulthood. Pediatric Annals. 44(11), e270-e273.

2. Willis CE, Slovis T L (2005). The ALARA concept in pediatric $\mathrm{cr}$ and dr: dose reduction in pediatric radiographic exams - a white paper conference. American Journal of Roentgenology, 184(2), 373-374.

3. Linet M, Kim K, Rajaraman P (2008). Children's exposure to diagnostic medical radiation and cancer risk: epidemiologic and dosimetric considerations. Pediatric 